\title{
Differential Effects of 5-HTTLPR Genotypes on Inhibition of Negative Emotional Information Following Acute Stress Exposure and Tryptophan Challenge
}

\author{
C Rob Markus*,' and Rudi De Raedt ${ }^{2}$ \\ 'Faculty of Psychology and Neuroscience, Department of Neuropsychology and Psychopharmacology, Universiteitssingel, Maastricht, \\ The Netherlands; '2Department of Experimental Clinical and Health Psychology, Ghent University, Ghent, Belgium
}

\begin{abstract}
Previous data suggest that a polymorphism at the serotonin (5-HT) transporter gene (5-HTTLPR) may influence stress resilience and stress-related depression symptoms due to interactions between brain 5-HT dysfunction and stress exposure. Although attentional bias for emotional information has been reliably observed in depression, the interaction between 5-HT transporter-linked promoter region (5-HTTLPR), brain 5-HT vulnerability, and acute stress on affective information processing has not yet been investigated. This study examines the effects of tryptophan (TRP) augmentation (indicating 5-HT manipulation) on inhibition of negative emotional information under stress in mainly female $S^{\prime} / S^{\prime}-v s L^{\prime} / L^{\prime}$-allele carriers. A total of I 5 female homozygotic short-allele $5-H T T L P R\left(S^{\prime} / S^{\prime}=S / S, S / L_{G}\right.$, $\left.L_{G} / L_{G}\right)$ and 13 female homozygotic long-allele 5-HTTLPR $\left(L^{\prime} / L^{\prime}=L_{A} / L_{A}\right)$ subjects were tested for mood and inhibition of emotional information in a double-blind, placebo-controlled design before and after stress exposure following TRP manipulation. Stress exposure significantly impaired inhibition of negative affective information only in $S^{\prime} / S^{\prime}$ carriers, whereas $L^{\prime} / L^{\prime}$ carriers even showed increased inhibition of negative information. The $S^{\prime} / S^{\prime}$ allele 5-HTTLPR genotype increases cognitive-attentional bias for negative emotional information under acute stress. As this bias is an important component of depression, this may be a mediating mechanism making $S^{\prime} / S^{\prime}$-allele carriers more vulnerability for stress-induced depression symptoms. Moreover, current data suggest that $L^{\prime} / L^{\prime}$-allele genotypes are more resilient, even increasing cognitive emotional (inhibitory) control after stress.

Neuropsychopharmacology (201I) 36, 819-826; doi: I0.1038/npp.2010.221; published online 8 December 2010
\end{abstract}

Keywords: 5-HTTLPR; emotion processing; serotonin; stress; tryptophan

\section{INTRODUCTION}

The identification of biological vulnerability factors for depression is an important challenge facing biological psychiatry today. Among the various biochemical processes involved, brain serotonin (5-HT) dysfunction appears to be a meaningful risk factor (Maes and Meltzer, 1995; Van Praag, 2004). 5-HT dysfunction manifests in depressed patients as lowered brain tryptophan (TRP) concentrations (eg, see Agren and Reibring, 1994; Maes et al, 1990); impaired 5-HT synthesis, release, reuptake, or metabolism (eg, see Maes and Meltzer, 1995; Malison et al, 1998; van Praag et al, 1970); or 5-HT receptor disturbances (eg, see Cowen et al, 1994; Sargent et al, 2000), whereas

*Correspondence: Dr CR Markus, Faculty of Psychology and Neuroscience, Department of Neuropsychology and Psychopharmacology, Room 2.773, Universiteitssingel 40, Maastricht 6229 ER, The Netherlands, Tel: +043-3882474, Fax: +043-3884196. E-mail: r.markus@psychology.unimaas.nl

Received 25 May 2010; revised 14 October 2010; accepted 3 November 2010 antidepressant drugs generally act by improving brain 5-HT function (Delgado et al, 1990; Delgado et al, 1993; Maes and Meltzer, 1995).

5-HT dysfunction in depression is promoted by a genetic vulnerability involving a polymorphism in the 5-HT transporter-linked promoter region (5-HTTLPR). This region encodes the 5-HT transporter (5-HTT) protein that controls 5 -HT reuptake and function, and which is the main target mechanism for antidepressant drugs (Serretti et al, 2007). The short-allele (S) variant of 5-HTTLPR is associated with fewer 5-HTT binding sites compared with the long-allele (L) variant (Heils et al, 1996; Mann et al, 2000) and is involved in 5-HT dysfunction during depression (Jans et al, 2007). Recently, the presence of an $A>G$ single-nucleotide polymorphism has been identified in the $\mathrm{L}$ allele, rendering an Lg variant (as opposed to La) that is functionally equivalent to the S-allele ( $\mathrm{Hu}$ et al, 2005; Wendland et al, 2006). However, 5-HT dysfunction in depression is also promoted by stress due to interactions between 5-HT and the hypothalamus-pituitary-adrenal (HPA) system (Firk and Markus, 2007; Van Praag, 2004). Hence, depression is 
often preceded by stress (Van Praag, 2004), and there is a positive association between the number of copies of the S-allele 5-HTTLPR and self-reports of past depressive responses to stressful events (Caspi et al, 2003; Jacobs et al, 2006; Wilhelm et al, 2006). However, attempts to replicate these findings have yielded mixed results (Risch et al, 2009).

Despite the suggestion from previous studies that stressful events might promote depression symptoms mostly in homozygous S-allele compared with homozygous L-allele 5-HTTLPR carriers, actual interactions between genetic 5-HT vulnerability, stress exposure, and depression have barely been investigated. A recent experimental study reveals evidence for enhanced HPA stress-responses exclusively in homozygous S-allele 5-HTTLPR carriers (Gotlib et al, 2008), but this experiment did not include the measurement of depression-specific cognitive-affective changes or of brain 5-HT vulnerability.

Depression specific changes can be adequately measured by negative affective priming (NAP) tasks that measure attentional bias for emotional information (Goeleven et al, 2006; Joormann, 2004). Hence, attentional bias for negative information is a hallmark feature of MDD (see Scher et al, 2005), which relates to impaired cognitive inhibition toward negative emotional material (Goeleven et al, 2006; Gotlib et al, 2005; De Raedt and Koster, 2010). In support, 5-HT is implicated in decreased attentional control over negative stimuli by modulating prefrontal-amygdala connectivity (see Cools et al, 2008), and S/S show enhanced emotional amygdala responses (Hariri and Holmes, 2006) and impaired disengagement to emotional information (Beevers et al, 2009).

Brain 5-HT vulnerability relates to an enhanced sensitivity to alterations in the 5-HT system (Jans et al, 2007). This can be measured by acute TRP depletion (Biggio et al, 1974; Carpenter et al, 1998; Nishizawa et al, 1997; Williams et al, 1999) that has been found to increase depression symptoms in individuals at risk for depression (Ruhe et al, 2007), including homozygous S-allele 5-HTTLPR carriers (Neumeister et al, 2002; Neumeister et al, 2006). However, because S/S-allele carriers may exhibit altered 5-HT sensitization to compensate lower 5-HTT expression (David et al, 2005; Moore et al, 2000), TRP challenge may be an alternative method to reveal 5-HT vulnerability associated with 5-HTTLPR. In support, TRP administration improved mood in S/S- not L/L-allele carriers (Markus and Firk, 2009).

The current study is the first to investigate the interaction between acute stress, 5-HTTLPR, and 5-HT vulnerability on the inhibition of negative emotional information. Based on previous assumptions, it is hypothesized that stress reduces the inhibition of negative information in S/S- not $\mathrm{L} / \mathrm{L}$-allele carriers and that TRP administration reduces this effect only in S/S-allele carriers.

\section{PATIENTS AND METHODS}

\section{Participants}

Students from Maastricht University completed a questionnaire package concerning general information (health, personal, or family history of medical or psychiatric complaints, smoking and drinking habits, caffeine consumption, weight and height, use of psychoactive drugs) and concerning relevant symptoms and psychopathology (Beck Depression Inventory, Inventory of College Students' recent life experiences (ICSRLE), Inadequacy/neuroticism Scale of the Dutch Personality Inventory, and the Social Complaints List). Exclusion criteria were health or medical complaints; personal or family history of psychiatric illness; history of medical illness; medication use; metabolic-, hormonal-, or intestinal diseases; irregular diet; deviant eating habits or excessive alcohol or drug use. Following this first selection, 90 participants attended a buccal sample extraction session to genotype for 5-HTTLPR (resulting in $26 \% \mathrm{~S} / \mathrm{S}, 46 \% \mathrm{~S} / \mathrm{L}$, and $28 \% \mathrm{~L} / \mathrm{L}$ ). As brain 5-HT vulnerabilities for stress are mainly found in homozygotes $S$ compared with homozygotes L-allele carriers (eg, see Neumeister et al, 2002; Caspi et al, 2003; Wilhelm et al, 2006; Zalsman et al, 2006), only homozygous S-allele (S/S, $\mathrm{S} / \mathrm{L}_{\mathrm{G}}, \mathrm{L}_{\mathrm{G}} / \mathrm{L}_{\mathrm{G}}$; classified as $\mathrm{S}^{\prime} / \mathrm{S}^{\prime}$ ) and homozygous L-allele $\left(\mathrm{L}_{\mathrm{A}} / \mathrm{L}_{\mathrm{A}}\right.$; classified as $\left.\mathrm{L}^{\prime} / \mathrm{L}^{\prime}\right)$ were then invited for a psychiatric structured interview (MINI: Sheehan et al, 1994) to double-check exclusion compliance and to receive information about the experiment. After invitation, before the psychiatric interview, a number of $8 \mathrm{~S}^{\prime} / \mathrm{S}^{\prime}$ and $12 \mathrm{~L}^{\prime} / \mathrm{L}^{\prime}$ subjects refrained from further participation because of shortage of time or other non-specified reasons.

A total of $15 \mathrm{~S}^{\prime} / \mathrm{S}^{\prime}$ and $13 \mathrm{~L}^{\prime} / \mathrm{L}^{\prime}$ female participants completed the experiment. Both groups included Caucasian participants with European (mainly Dutch) background. They all revealed normal body mass indexes (BMI between 20 and $25 \mathrm{~kg} / \mathrm{m}^{2}$; mean $22 \pm 2$ ), were non-smokers, and were requested not to use alcohol or any kind of drugs $24 \mathrm{~h}$ before and during the study. Both groups did not differ in age, BMI, and additional relevant symptoms. The study was approved by the Medical Ethics Committee of the Academic Hospital Maastricht (CTCM azM; Maastricht; The Netherlands) and the procedures followed were in accordance with the Helsinki Declaration of 1975 as revised in 1983. All subjects gave their written informed consent and were paid for participation.

\section{Design and Procedure}

A placebo-controlled, double-blind, crossover design was used. During two sessions, subjects were monitored for NAP before and after stress exposure following intake of TRP or placebo (PLC). The order of presentation of the treatment conditions was counterbalanced within groups; both sessions were separated by 1 week. All subjects were tested in the mid-late follicular phase of their menstrual cycle or when actually taking oral contraceptives. An illustration of the design is given in Figure 1.

All participants fasted overnight; except for water or tea without sugar. On each experimental day, three participants arrived at 0800, 0900, and 1000 hours, respectively. Capsules were consumed $1 \mathrm{~h}$ before arrival. After arrival and a subsequent $15 \mathrm{~min}$ rest period, mood and NAP was assessed. Then, participants were exposed to a stressinducing procedure followed by a second mood and NAP measure. 


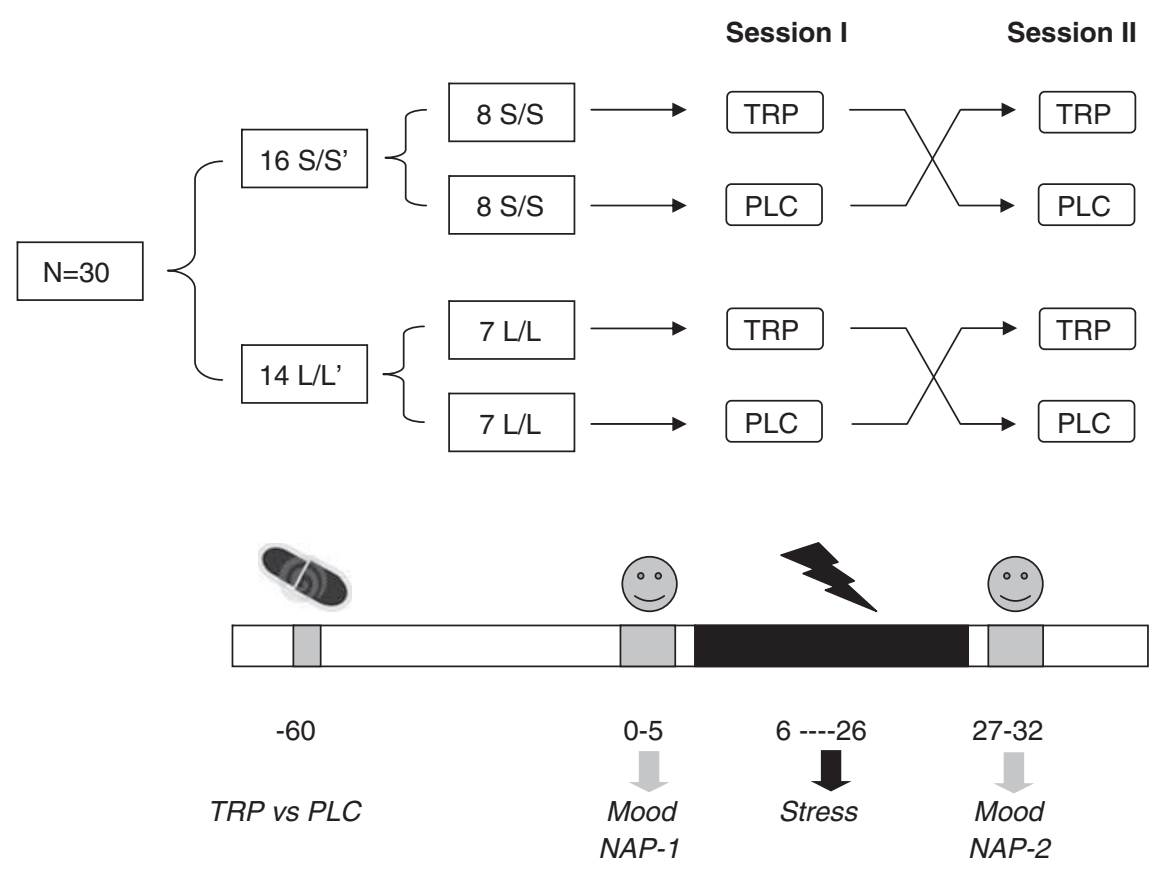

Figure I Schematic overview of the study design.

\section{Stress Exposure}

Subjects were placed in front of a camera for 20 min while completing 2-min serial subtraction sessions and coldpressor exposures. At unpredictable occasions, they were signaled to start at a certain number and count backwards by seven as quickly as possible. If they made a mistake, they were interrupted by the experimenter and had to start over. In addition, at unpredictable occasions while continuing counting, they had to place their non-preferred hand on a $1.5^{\circ} \mathrm{C}$ cold plate for as long as possible (with a maximum of $2 \mathrm{~min}$ ). For cold-pressor exposure, a cooler device was used composed of a copperplate surface $(150 \times 230 \mathrm{~mm})$ that was thermoelectrically cooled at a constant level by way of Peltier (TEC) devices. Backward counting was initiated at four different unpredictable $180 \pm 30 \mathrm{~s}$ time intervals using different numbers $(400,425,530$, or 840$)$ that were counterbalanced within-subjects. Cold-pressor signals appeared at six unpredictable $120 \pm 60$ s time intervals either during $(85 \%)$ or between $(15 \%)$ counting sessions.

\section{TRP Challenge}

To increase plasma TRP, $0.8 \mathrm{~g}$ TRP as compared with $0.8 \mathrm{~g}$ PLC (cellulose) capsules were used. Comparable intake of TRP has been shown to increase plasma TRP availability (TRP/LNAA ratio) with $190 \%$ 60-90 min after intake (Markus et al, 2008). Capsules were identical and subjects were instructed to swallow them whole with water.

\section{Positive and Negative Affect Scale (PANAS)}

The PANAS (Watson et al, 1988) consists of two 10-item mood scales, a positive mood scale and a negative mood scale. These items are randomly presented and participants have to respond on a scale ranging from 1 (totally disagree) to 5 (totally agree).

\section{Negative Affective Priming}

The NAP task included $(5 \times 5.5 \mathrm{~cm})$ colored pictures of positive $(n=33)$, negative $(n=33)$, or neutral $(n=22)$ faces that were selected from the Karolinska Emotional Directed Faces database (Lundqvist and Ohman, 1998) and on the basis of previous validation (Goeleven et al, 2006). Pictures were divided into eight lists (based on stimulus type) of 11 randomly chosen pictures sharing the same valence: one negative and one positive prime target list, one negative and one positive prime distracter list, one negative and one positive probe target list, and two neutral probe distracter lists. Pictures were indicated as target or distracter by a black or gray frame. Participants were instructed to evaluate the valence of the target picture - indicated by the color of the frame-as accurately as possible by a response key while ignoring the distracter picture. Each trial started with a fixation cross (for $1000 \mathrm{~ms}$ ) after which two emotional faces appeared in the upper and the lower half of the screen (one surrounded by a gray frame and one by a black frame) until responding (see Figure 2).

After training (including 32 trials), a sequence of 256 test trials (separated by a $1000 \mathrm{~ms}$ blank screen) followed that were divided into 8 blocks of 16 prime and probe trials. The response cue (gray or black frame) and key assignment was counterbalanced between subjects and the spatial position of the target and the distracter - as well as sequence of congruent and incongruent prime-probe trials-were randomly assigned from trial to trial. Reaction time (RT) to the probe trials for both the positive and negative trials were reordered (RT below $300 \mathrm{~ms}$ and above $2000 \mathrm{~ms}$ were excluded (see Goeleven et al, 2006) and NAP scores were 


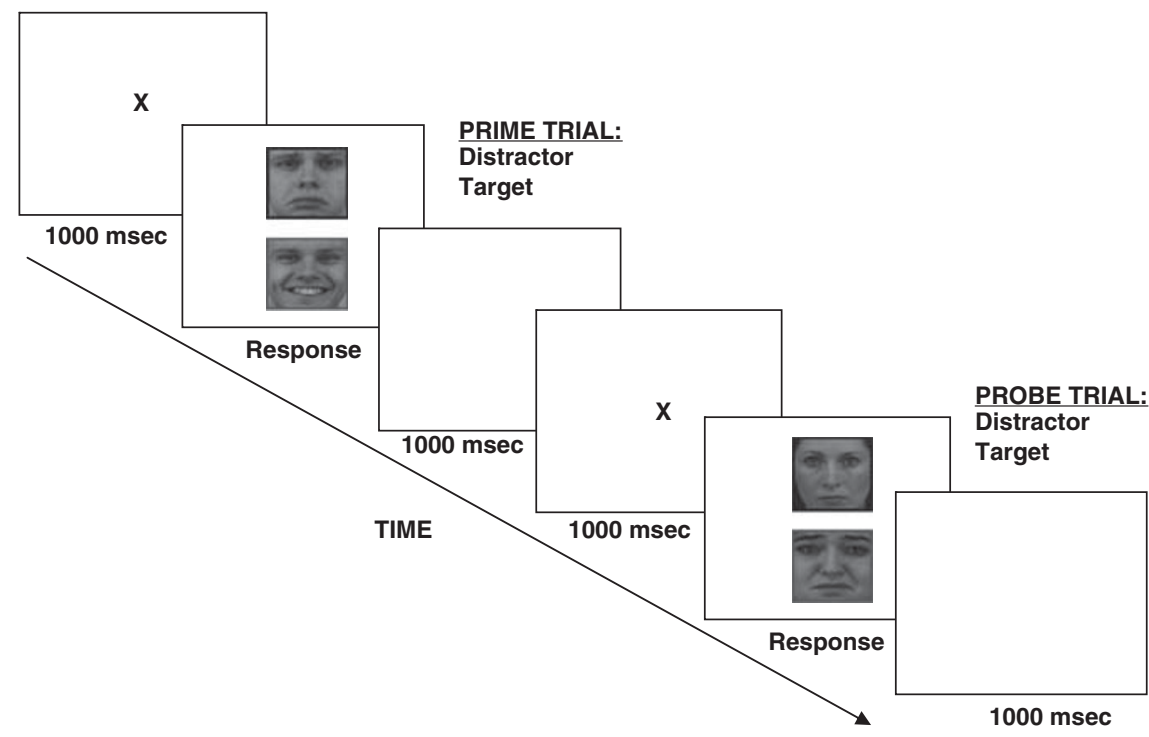

Figure 2 Negative affective priming design.

calculated by subtracting RT to control trials from RT to experimental trials.

\section{Buccal Cells for Tri-Allelic 5-HTTLPR Polymorphism}

Buccal cell samples for 5-HTTLPR genotype determination were obtained using sterile swabs (Omni Swabs, Whatman's, Hertogenbosch, The Netherlands). Genomic DNA was isolated by QIamp DNA Mini Kits from Qiagen (Westburg, Leusden, The Netherlands) and 5-HTTLPR genotyping was performed using the PCR protocol according to Glatz et al (2003). In compliance with previous work (eg, see Neumeister et al, 2006; Walderhaug et al, 2007; Zalsman et al, 2006), tri-allelic variants were reclassified into a bi-allelic model as follows: $\mathrm{S} / \mathrm{S}, \mathrm{S} / \mathrm{L}_{\mathrm{G}}$, and $\mathrm{L}_{\mathrm{G}} / \mathrm{L}_{\mathrm{G}}$ were classified as $\mathrm{S}^{\prime} / \mathrm{S}^{\prime}$ and $\mathrm{L}_{\mathrm{A}} / \mathrm{L}_{\mathrm{A}}$ as $\mathrm{L}^{\prime} / \mathrm{L}^{\prime}$.

\section{Statistical Analysis}

Data were first examined for accuracy of data entry, missing values, and normal distributions. Hardy-Weinberg equilibrium was determined on the original 5-HTTLPR database $(n=90)$ using $\chi^{2}$ tests, revealing that the genotype frequencies of $S^{\prime} / S^{\prime} \quad(n=24), \quad S / L \quad(n=40)$ and $L^{\prime} / L^{\prime}$ $(n=26)$ did not depart from Hardy-Weinberg equilibrium $\left(\chi_{(1)}^{2}=1.45 ; p=0.23\right)$. Data were analyzed by means of repeated measures Anova (GLM: SPSS 12.0 for Windows) with one between-subjects factor Genotype $\left(S^{\prime} / S^{\prime} v s L^{\prime} / L^{\prime}\right)$ and two within-subjects factors, Treatment (TRP vs PLC) and Stress (prestress vs post-stress), on mood (PANAS) and NAP. Regarding NAP, repeated measures were conducted on difference RT scores between control and experimental probe trials, separately for the positive and negative trials. Although we counterbalanced for the order of treatment, Order of Treatment was preliminary taken as a between-subjects factor. Because Order of Treatment did not contribute to any of the scores, final analyses were performed with only Genotype as between-subjects factor.
All statistics are evaluated at a two-tailed significance level of $5 \%$. Data are reported as means $\pm \mathrm{SD}$.

\section{RESULTS}

\section{PANAS}

Repeated measure analyses were conducted on the PANAS scores for positive and negative mood with Genotype $\left(S^{\prime} / S^{\prime} v s L^{\prime} / L^{\prime}\right)$ as between-subjects factor and Treatment (TRP vs PLC) and Stress (prestress vs post-stress) as withinsubjects factors. Analysis revealed an effect of Stress on positive feelings $(\mathrm{F}(1,26)=13.49, p=0.001$; power $=0.95)$ and negative feelings $(\mathrm{F}(1,26)=15.52, p=0.001$; power $=$ $0.94)$; indicating a reduction in positive feelings post-stress $(2 \pm 0.7)$ compared with prestress $(2.6 \pm 0.7)$ and an increase in negative feelings post-stress $(1.3 \pm 0.4)$ compared with prestress $(1.0 \pm 0.2)$. Regarding negative mood, analysis revealed an interaction of Treatment $\times$ Genotype $(\mathrm{F}(1,26)=6.01, p=0.02 ;$ power $=0.70)$, Treatment $\times$ Stress $(\mathrm{F}(1,26)=4.58, p=0.042$; power $=0.60)$, and a marginally three-way interaction of Treatment $\times$ Stress $\times$ Genotype $(\mathrm{F}(1,26)=4.2, \quad p=0.041 ; \quad$ power $=0.50)$. As shown in Figure $3, S^{\prime} / S^{\prime}$ reported a modest increase in negative feelings post-stress $(1.6 \pm 0.9)$ compared with prestress $(1.0 \pm 0.12)$ after PLC that was absent after TRP $(1.1 \pm 0.3$ post-stress compared with $1.1 \pm 0.2$ prestress).

\section{Negative Affective Priming}

Repeated measure analyses were conducted on the NAP scores for positive and negative trials with Genotype $\left(S^{\prime} / S^{\prime}\right.$ vs $\mathrm{L}^{\prime} / \mathrm{L}^{\prime}$ ) as between-subjects factor and Treatment (TRP vs PLC) and Stress (prestress vs post-stress) as within-subjects factors. Analysis revealed an interaction of Stress $\times$ Genotype $(\mathrm{F}(1,26)=16.84, p<0.001$; power $=0.95)$ for the negative trials; indicating an effect of stress exposure on inhibition of negative emotional information depending on 
5-HTTLPR. As illustrated in Figure 4, stress exposure significantly impaired inhibition of negative emotional information in $S^{\prime} / S^{\prime}(p<0.0001)$, whereas in $\mathrm{L}^{\prime} / \mathrm{L}^{\prime}$ inhibition of negative information improve (higher NAP) by stress exposure $(p=0.027)$.

\section{DISCUSSION}

The aim of the present study was to explore whether the $S^{\prime} / S^{\prime}$-allele variant compared with the $L^{\prime} / L^{\prime}$-allele variant of the 5-HTTLPR increases the negative effects of stress exposure on the inhibition of affective information. Assuming 5-HTergic vulnerability in carriers of the low-expressing 5-HTTLPR, $S^{\prime} / S^{\prime}$-allele carriers were also expected to be less affected by stress following TRP

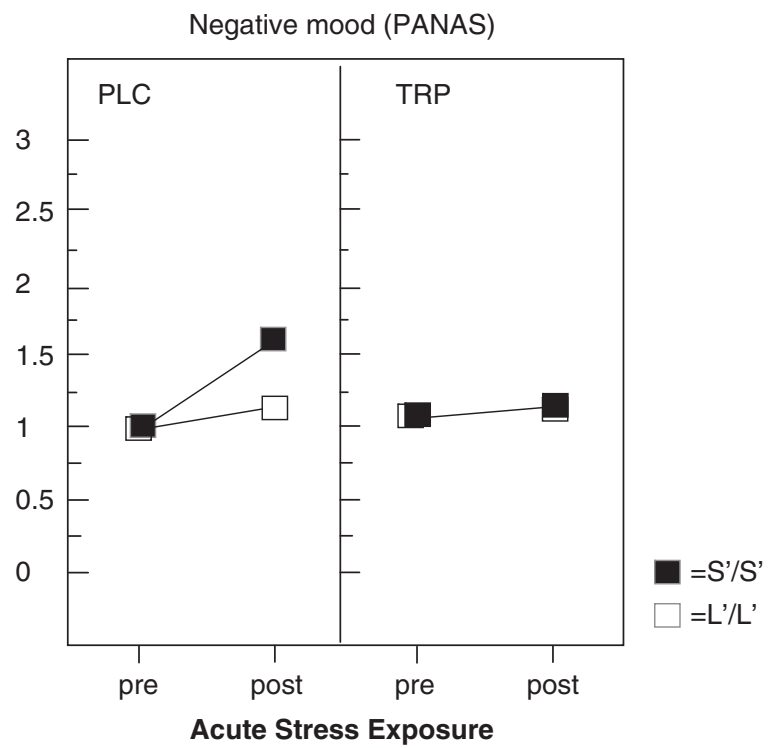

Figure $3 S^{\prime} / S^{\prime}$ allele reported an increase in negative feelings post-stress compared with prestress after PLC that was prevented after TRP (poststress compared with prestress). compared with PLC. Results revealed that stress exposure significantly reduced mood and that only in $S^{\prime} / S^{\prime}$-allele carriers did stress impairs the successful inhibition of negative affective information.

\section{Stress and NAP}

To induce acute stress, subjects completed serial subtraction sessions in combination with frequent cold-pressor exposures. Both the cold-pressor exposures (Isowa et al, 2006) and counting tasks (Dickerson and Kemeny, 2004) have been shown to be sufficient to induce stress; repeated exposures given in a variable and unpredictable manner have induced even more severe stress responses (Markus, 2007). In addition, the stress procedure in the current study was sufficient to induce negative mood responses.

In line with our expectation, exposure to the stress procedure increased the facilitation of negative information processing only in $S^{\prime} / S^{\prime}$-allele carriers. Hence, exclusively in $S^{\prime} / S^{\prime}$, acute stress speeded up recognition for negative facial expressions during experimental NAP conditions (responding to negative probe targets that are preceded by prime distracters with the same negative valence) compared with control conditions (responding to negative probe targets that are preceded by prime distracters with an opposite valence). Because this reduced NAP effect represents an impaired inhibitory function toward negative affective information (Joormann, 2004; Goeleven et al, 2006), the current findings suggest that $S^{\prime} / S^{\prime}$-allele carriers are more susceptible to the deteriorating effects of stress exposure on the successful inhibition of negative information. In contrast, $L^{\prime} / L^{\prime}$-allele carriers not only did not show these vulnerabilities, but also they were more successful at inhibiting negative information under stress (indicating that this variant could be a marker of resilience against the detrimental effects of stress).

The current 'boosting' effect of acute stress on the facilitation of negative information processing in $S^{\prime} / S^{\prime}$-allele carriers complies with recent findings that homozygous $S^{\prime}$ allele are most susceptible to the negative affective (Firk and

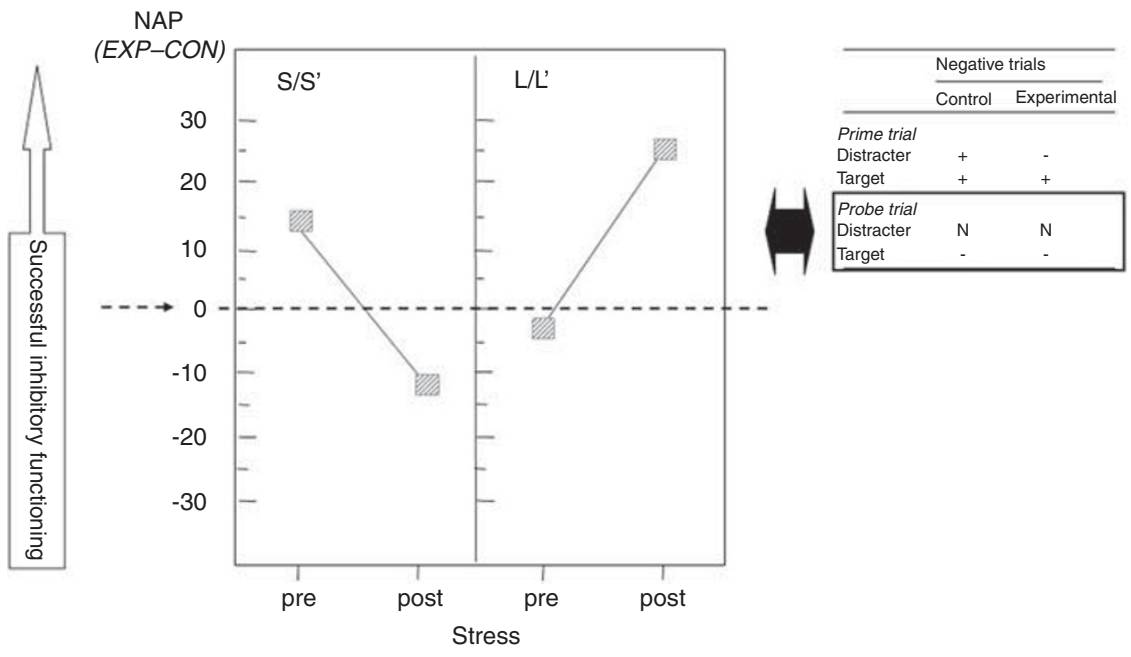

Figure 4 Acute stress exposure significantly impaired inhibition of negative emotional information (reduced NAP) only in $S^{\prime} / S^{\prime}$ genotypes $(p<0.000 \mathrm{I})$, whereas in $L^{\prime} / L^{\prime}$ genotypes inhibition of negative information improved (higher NAP) by stress exposure $(p=0.025)$. 
Markus, 2009) and hormonal (Gotlib et al, 2008) effects of stress exposure and to the depressogenic effects of life events (Caspi et al, 2003; Uher and McGuffin, 2008). In addition, the current study elaborates on previous findings by showing that the enhanced vulnerability in $S^{\prime} / S^{\prime}$-allele carriers for stress-related depression may be mediated by a stress-induced impairment in the ability to inhibit negative information. This also complies with findings from imaging studies showing that $\mathrm{S}$-allele carriers exhibit enhanced amygdala responses to negative facial expressions (Pezawas et al, 2005; Dannlowski et al, 2008). This result has been attributed to a reduced amygdala-to-prefrontal-cortex connectivity (a reduced inhibition of the amygdala) that is also observed in depression (Siegle et al, 2007).

The current stress-induced increase in negative information processing in $S^{\prime} / S^{\prime}$-allele carriers can be explained by the mood-congruent hypothesis that negative affective interruption facilitates continued processing of negative information. In addition, the previously demonstrated depressogenic effects of life events on S/S-allele carriers (Caspi et al, 2003; Uher and McGuffin, 2008) may be moderated by a stress-induced increase in attentional bias allowing for maintained attention on negative material. Thus, in $S^{\prime} / S^{\prime}$-allele carriers, stress may reduce the successful inhibition of distracting negative stimuli. In fact, this stressinduced disturbed inhibitory functioning is thought to be a core factor that is related to the previously observed difficulties in depressed patients to disengage attention away from negative information (Leyman et al, 2007). In addition, comparable both with our current findings in healthy $S^{\prime} / S^{\prime}-$ allele carriers and with the assumption that $S^{\prime} / S^{\prime}$-allele carriers are more prone to develop depression, depressed subjects have also been shown to exhibit a reduced ability to inhibit negative information during a NAP task (Goeleven et al, 2006; Leyman et al, 2010).

To reveal whether $S^{\prime} / S^{\prime}$ are more susceptible to the effects of stress due to brain 5-HT vulnerability, a TRP challenge was used in the current study. Based on previous studies reporting a 5-HT vulnerability to the mood-lowering effects of ATD in $S^{\prime} / S^{\prime}$-allele carriers (Neumeister et al, 2006; Neumeister et al, 2002; Roiser et al, 2006), it was hypothesized that TRP may reduce the negative stress effects. The current findings, however, did not reveal significant TRP effects on NAP and only marginally (reducing) effects on negative mood in $S^{\prime} / S^{\prime}$ carriers.

\section{Limitations}

One point that deserves special attention is the relatively small sample size of the $S^{\prime} / S^{\prime}$ and $L / L$ groups. Even though the current findings reveal powerful genotype $\times$ stress interaction effects on NAP, the sample sizes might have been too small to also detect TRP $\times$ stress interactions on NAP. Another point of attention is that the current findings only included female subjects. It therefore remains necessary to conduct a comparable experiment in a comparable sample of male participants.

\section{Conclusion}

The current findings reveal that stress exposure in female $S^{\prime} / S^{\prime}$ - not $L^{\prime} / L^{\prime}$-allele carriers reduces inhibitory functioning for negative information. Because $S^{\prime} / S^{\prime}$ carriers are found to be vulnerable to the negative depressogenic effects of stress, the current data is in line with the assumption that a stressby-depression interaction in $S^{\prime} / S^{\prime}$-allele carriers may be promoted by a stress-induced facilitation of negative emotional information.

\section{DISCLOSURE}

All authors ensure the integrity of the work and none of them has any direct or indirect financial or personal interests, or conflict of interest, to the subject matter of the manuscript.

\section{REFERENCES}

Agren H, Reibring L (1994). PET studies of presynaptic monoamine metabolism in depressed patients and healthy volunteers. Pharmacopsychiatry 27: 2-6.

Beevers CG, Wells TT, Ellis AJ, McGeary J (2009). Association of the serotonin ransporter gene promoter region (5-HTTLPR) polymorphism with biased attention for emotional stimuli. J Abnorm Psychol 118: 670-681.

Biggio G, Fadda F, Fanni P, Tagliamonte A, Gessa GL (1974). Rapid depletion of serum tryptophan, brain tryptophan, serotonin and 5-hydroxyindoleacetic acid by a tryptophan-free diet. Life Sci 14: 1321-1329.

Carpenter LL, Anderson GM, Pelton GH, Gudin JA, Kirwin PD, Price LH et al (1998). Tryptophan depletion during continuous CSF sampling in healthy human subjects. Neuropsychopharmacology 19: 26-35.

Caspi A, Sugden K, Moffitt TE, Taylor A, Craig IW, Harrington H et al (2003). Influence of life stress on depression: moderation by a polymorphism in the 5-HTT gene. Science 301: 386-389.

Cools R, Roberts AC, Robbins TW (2008). Serotoninergic regulation of emotional and behavioural control processes. Trends cogn Sci 12: 31-40.

Cowen PJ, Power AC, Ware CJ, Anderson IM (1994). 5-HT1A receptor sensitivity in major depression. A neuroendocrine study with buspirone. Br J Psychiatry 164: 372-379.

Dannlowski U, Ohrmann P, Bauer J, Deckert J, Hohoff C, Kugel H et al (2008). 5-HTTLPR biases amygdala activity in response to masked facial expressions in major depression. Neuropsychopharmacology 33: 418-424.

David SP, Murthy NV, Rabiner EA, Munafo MR, Johnstone EC, Jacob $\mathrm{R}$ et al (2005). A functional genetic variation of the serotonin (5-HT) transporter affects 5-HT1A receptor binding in humans. J Neurosci 25: 2586-2590.

De Raedt R, Koster EHW (2010). Understanding vulnerability for depression from a cognitive neuroscience perspective: a reappraisal of attentional factors and a new conceptual framework. Cogn Affect Behav Neurosci 10: 50-70.

Delgado PL, Charney DS, Price LH, Aghajanian GK, Landis H, Heninger GR (1990). Serotonin function and the mechanism of antidepressant action. Reversal of antidepressant-induced remission by rapid depletion of plasma tryptophan. Arch Gen Psychiatry 47: 411-418.

Delgado PL, Miller HL, Salomon RM, Licinio J, Heninger GR, Gelenberg AJ et al (1993). Monoamines and the mechanism of antidepressant action: effects of catecholamine depletion on mood of patients treated with antidepressants. Psychopharmacol Bull 29: 389-396.

Dickerson SS, Kemeny ME (2004). Acute stressors and cortisol responses: a theoretical integration and synthesis of laboratory research. Psychol Bull 130: 355-391. 
Firk C, Markus CR (2007). Review: Serotonin by stress interaction: a susceptibility factor for the development of depression? J Psychopharmacol 21: 538-544.

Firk C, Markus CR (2009). Differential effects of 5-HTTLPR genotypes on mood, memory and attention bias following acute tryptophan depletion and stress exposure. Psychopharmacology (Berl) 203: 805-818.

Glatz K, Mossner R, Heils A, Lesch KP (2003). Glucocorticoidregulated human serotonin transporter (5-HTT) expression is modulated by the 5-HTT gene-promotor-linked polymorphic region. J Neurochem 86: 1072-1078.

Goeleven E, De Raedt R, Baert S, Koster EH (2006). Deficient inhibition of emotional information in depression. J Affect Disord 93: 149-157.

Gotlib IH, Joormann J, Minor KL, Hallmayer J (2008). HPA axis reactivity: a mechanism underlying the associations among 5-HTTLPR, stress, and depression. Biol Psychiatry 63: 847-851.

Gotlib IH, Neubauer YD, Joorman J (2005). Selective attention in dysphoric individuals: the role of affective interference and inhibition. Cognit ther res 29: 417-432.

Hariri AR, Holmes A (2006). The serotonin transporter and the genetics of affect regulation: the role of the serotonin transporter in neural function. Trends cogn Sci 10: 182-191.

Heils A, Teufel A, Petri S, Stober G, Riederer P, Bengel D et al (1996). Allelic variation of human serotonin transporter gene expression. J Neurochem 66: 2621-2624.

Hu X, Oroszi G, Chun J, Smith TL, Goldman D, Schuckit MA (2005). An expanded evaluation of the relationship of four alleles to the level of response to alcohol and the alcoholism risk. Alcohol Clin Exp Res 29: 8-16.

Isowa $\mathrm{T}$, Ohira $\mathrm{H}$, Murashima S (2006). Immune, endocrine and cardiovascular responses to controllable and uncontrollable acute stress. Biol Psychol 71: 202-213.

Jacobs N, Kenis G, Peeters F, Derom C, Vlietinck R, van Os J (2006). Stress-related negative affectivity and genetically altered serotonin transporter function: evidence of synergism in shaping risk of depression. Arch Gen Psychiatry 63: 989-996.

Jans LA, Riedel WJ, Markus CR, Blokland A (2007). Serotonergic vulnerability and depression: assumptions, experimental evidence and implications. Mol Psychiatry 12: 522-543.

Joormann J (2004). Attentional bias in dysphoria; the role of inhibitory processes. Cogn Emot 18: 125-147.

Leyman L, De Raedt R, Schacht R, Koster HW (2007). Attentional biases for angry faces in unipolar depression. Psychological Medicine 37: 393-402.

Leyman L, De Raedt R, Vanderhasselt MA, Baeken C (2010). Effects of repetitive transcranial magnetic stimulation of the dorsolateral prefrontal cortex on the attentional processing of emotional information in major depression: A pilot study. Psychiatry Research (in press).

Lundqvist DF, A, Ohman A (1998). The karolinska directed emotional faces-KDEF.

Maes M, Jacobs MP, Suy E, Minner B, Leclercq C, Christiaens F et al (1990). Suppressant effects of dexamethasone on the availability of plasma L-tryptophan and tyrosine in healthy controls and in depressed patients. Acta Psychiatr Scand 81: 19-23.

Maes M, Meltzer HY (1995). The serotonin hypothesis of major depression. In: Bloom FE, Kupfer DJ (eds) Psychopharmacology: The Fourth Generation of Progress. Raven Press: New York, pp 933-944.

Malison RT, Price LH, Berman R, van Dyck CH, Pelton GH, Carpenter L et al (1998). Reduced brain serotonin transporter availability in major depression as measured by [123I]-2 beta-carbomethoxy-3 beta-(4-iodophenyl)tropane and single photon emission computed tomography. Biol Psychiatry 44: 1090-1098.

Mann JJ, Huang YY, Underwood MD, Kassir SA, Oppenheim S, Kelly TM et al (2000). A serotonin transporter gene promotor polymorphism (5-HTTLPR) and prefrontal cortical binding in major depression and suicide. Arch Gen Psychiatry 57: $729-738$

Markus C, Firk C (2009). Differential effects of tri-allelic 5-HTTLPR polymorphisms in healthy subjects on mood and stress performance after tryptophan challenge. Neuropsychopharmacology 34: 2667-2674.

Markus CR (2007). Effects of carbohydrates on brain tryptophan availability and stress performance. Biol Psychol 76: 83-90.

Markus CR, Firk C, Gerhardt C, Kloek J, Smolders GF (2008). Effect of different tryptophan sources on amino acids availability to the brain and mood in healthy volunteers. Psychopharmacology (Berl) 201: 107-114.

Moore P, Landolt HP, Seifritz E, Clark C, Bhatti T, Kelsoe J et al (2000). Clinical and physiological consequences of rapid tryptophan depletion. Neuropsychopharmacology 23: 601-622.

Neumeister A, Hu XZ, Luckenbaugh DA, Schwarz M, Nugent AC, Bonne O et al (2006). Differential effects of 5-HTTLPR genotypes on the behavioral and neural responses to tryptophan depletion in patients with major depression and controls. Arch Gen Psychiatry 63: 978-986.

Neumeister A, Konstantinidis A, Stastny J, Schwarz MJ, Vitouch O, Willeit $\mathrm{M}$ et al (2002). Association between serotonin transporter gene promoter polymorphism (5HTTLPR) and behavioral responses to tryptophan depletion in healthy women with and without family history of depression. Arch Gen Psychiatry 59: 613-620.

Nishizawa S, Benkelfat C, Young SN, Leyton M, Mzengeza S, de Montigny C et al (1997). Differences between males and females in rates of serotonin synthesis in human brain. Proc Natl Acad Sci USA 94: 5308-5313.

Pezawas L, Meyer-Lindenberg A, Drabant EM, Verchinski BA, Munoz KE, Kolachana BS et al (2005). 5-HTTLPR polymorphism impacts human cingulate-amygdala interactions: a genetic susceptibility mechanism for depression. Nat Neurosci 8: 828-834.

Risch N, Herrell R, Lehner T, Liang KY, Eaves L, Hoh J et al (2009). Interaction between the serotonin transporter gene (5-HTTLPR), stressful life events, and risk of depression; a meta-analysis. JAMA 301: 2462-2471.

Roiser JP, Blackwell AD, Cools R, Clark L, Rubinsztein DC, Robbins TW et al (2006). Serotonin transporter polymorphism mediates vulnerability to loss of incentive motivation following acute tryptophan depletion. Neuropsychopharmacology 31: 2264-2272.

Ruhe HG, Mason NS, Schene AH (2007). Mood is indirectly related to serotonin, norepinephrine and dopamine levels in humans: a meta-analysis of monoamine depletion studies. Mol Psychiatry 12: 331-359.

Sargent PA, Kjaer KH, Bench CJ, Rabiner EA, Messa C, Meyer J et al (2000). Brain serotonin1A receptor binding measured by positron emission tomography with [11C]WAY-100635: effects of depression and antidepressant treatment. Arch Gen Psychiatry 57: 174-180.

Scher CD, Ingram RE, Segal ZV (2005). Cognitive reactivity and vulnerability: empirical evaluation of construct activation and cognitive diatheses in unipolar depression. Psychol Rev 25: 487-510.

Serretti A, Kato M, De Ronchi D, Kinoshita T (2007). Meta-analysis of serotonin transporter gene promotor polymorphism (5HTTLPR) association with selective serotonin reuptake inhibitor efficacy in depressed patients. Mol Psychiatry 12: 247-257.

Sheehan D, Lecrubier Y, Janavs J, Knapp E, Weiller E (1994). MINI International Neuropsychiatric Interview. University of South Florida: Tampa, FL.

Siegle GJ, Thompson W, Carter CS, Steinhauer SR, Thase ME (2007). Increased amygdala and decreased dorsolateral prefrontal BOLD responses in unipolar depression: related and independent features. Biol Psychiatry 61: 198-209. 
5-HTTLPR, stress and attention bias CR Markus and R De Raedt

Uher R, McGuffin P (2008). The moderation by the serotonin transporter gene of environmental adversity in the aetiology of mental illness: review and methodological analysis. Mol Psychiatry 13: 131-146.

Van Praag HM (2004). Can stress cause depression? Prog Neuropsychopharmacol Biol Psychiatry 28: 891-907.

van Praag HM, Korf J, Puite J (1970). 5-Hydroxyindoleacetic acid levels in the cerebrospinal fluid of depressive patients treated with probenecid. Nature 225: 1259-1260.

Walderhaug E, Magnusson A, Neumeister A, Lappalainen J, Lunde $\mathrm{H}$, Refsum $\mathrm{H}$ et al (2007). Interactive effects of sex and 5-HTTLPR on mood and impulsivity during tryptophan depletion in healthy people. Biol Psychiatry 62: 593-599.

Watson D, Clark LA, Tellegen A (1988). Development and validation of brief measures of positive and negative affect: the PANAS scales. J Pers Soc Psychol 54: 1063-1070.
Wendland JR, Martin BJ, Kruse MR, Lesch KP, Murphy DL (2006). Simultaneous genotyping of four functional loci of human SLC6A4, with a reappraisal of 5-HTTLPR and rs25531. Mol Psychiatry 11: 224-226.

Wilhelm K, Mitchell PB, Niven H, Finch A, Wedgwood L, Scimone A et al (2006). Life events, first depression onset and the serotonin transporter gene. Br J Psychiatry 188: 210-215.

Williams WA, Shoaf SE, Hommer D, Rawlings R, Linnoila M (1999). Effects of acute tryptophan depletion on plasma and cerebrospinal fluid tryptophan and 5-hydroxyindoleacetic acid in normal volunteers. J Neurochem 72: 1641-1647.

Zalsman G, Huang YY, Oquendo MA, Burke AK, Hu XZ, Brent DA et al (2006). Association of a triallelic serotonin transporter gene promoter region (5-HTTLPR) polymorphism with stressful life events and severity of depression. Am J Psychiatry 163: $1588-1593$. 